\title{
The impact of caffeic acid phenethyl ester, chrysin and ethanolic extracts of propolis on PLD1 gene expression in AGS cell line
}

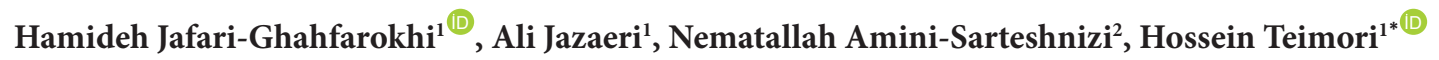 \\ ${ }^{1}$ Cellular and Molecular Research Center, Basic Health Sciences Institute, Shahrekord University of Medical Sciences, Shahrekord, Iran \\ ${ }^{2}$ Department of Biology, Faculty of Science, University of Mohaghegh Ardabili, Ardabil, Iran
}

\section{A R T I C L E I N F O}

Article Type:

Original Article

Article History:

Received: 27 April 2019

Accepted: 7 June 2019

\section{Keywords:}

Cancer

Caffeic acid phenethyl ester

Chrysin

PLD1 gene

Propolis

\begin{abstract}
A B S T R A C T
Introduction: Up-regulation of phospholipase $\mathrm{D}(\mathrm{PLD})$ is functionally related to tumorigenesis and oncogenic signals. Chrysin, caffeic acid phenethyl ester (CAPE) and ethanolic extract of propolis (EEP) are three safe compounds which have been shown to possess antiproliferative, antioxidant, anti-inflammatory and antineoplastic properties. In this study, the effects of these three compounds on PLD1 gene expression were examined in AGS cell line.

Methods: After determining the appropriate concentrations of EEP, CAPE, and chrysin, AGS cells were cultured in mediums with proper ratios of the compounds. AGS cells were maintained in exponential growth and the culture mediums refreshed every other day. Finally, after extracting total RNA from AGS cells, real-time PCR was performed to evaluate the mRNA expression of PLD1 in the presence of each compound.

Results: CAPE decreased the mRNA level of PLD1 gene in a dose-dependent manner. A solution with $30 \mu \mathrm{M}$ concentration of CAPE was the effective dose in comparison to control group as well as 15 and $20 \mu \mathrm{M}$ concentrations of the compound, whereas no changes were observed in the presence of EEP and chrysin.

Conclusion: Taken together, the results of the study indicated that CAPE might exert its antineoplastic effect by targeting PLD1 expression in AGS cell line.
\end{abstract}

Implication for health policy/practice/research/medical education:

Caffeic acid phenethyl ester (CAPE) can effectively inhibit cell proliferation in gastric cancer cell line and might be useful in the treatment of patients with gastric cancer.

Please cite this paper as: Jafari-Ghahfarokhi H, Jazaeri A, Amini-Sarteshnizi N, Teimori H. The impact of caffeic acid phenethyl ester, chrysin and ethanolic extracts of propolis on PLD1 gene expression in AGS cell line. J Herbmed Pharmacol. 2019;8(4):308313. doi: 10.15171/jhp.2019.45.

\section{Introduction}

On the molecular level, various factors can have effects on incidence and progression of cancers, including environmental factors, epigenetics and changes in specific genes expression (1-3). In many cancers, chemotherapy resistance is a common phenomenon and the major limitation in their treatment (4). Therefore, finding new ways and approaches to improve the life quality of patients with cancer or treating them, is quite crucial. Dietary supplements or alternatives to medication have become increasingly popular and the main focus to improve naturebased compounds with chemopreventive properties $(5,6)$. Chrysin, caffeic acid phenethyl ester (CAPE) and ethanolic extract of propolis (EEP) are three safe compounds and potential adjuvant therapies for patients with advanced cancers (7). CAPE is a polyphenolic compound which has influence on some of the cellular processes, including cell survival and proliferation (8). Chrysin and EEP are two active compounds that can be found in honey. These three compounds are considered to possess antitumor properties (7). It has been shown that they have influence on some important cell activities such as proliferation, apoptosis, and viability, in some cancer cell lines. They can exert their anticancer effects through several signaling pathways and genes $(9,10)$. Phospholipase D (PLD) is a member of phospholipase enzymes superfamily with two 
major isoforms, including PLD1and PLD2. Phospholipase D1 catalyzes the hydrolysis of phosphatidylcholin which leads to production of phosphatidic acid and free choline. PLD1 gene and its protein product become activated in some cancer cell lines, such as gastric cancer (11). Studies in glioma cells confirmed that the overexpression of PLD increases invasion via elevating $M M P$-2 gene transcription through NF-kB mediated signaling pathways (12). In the present study, by using real time PCR, the effects of CAPE, EEP, and chrysin compounds on PLD1 gene expression were analyzed in human gastric cancer cell line (AGS cell line).

\section{Materials and methods}

Chemicals and reagents

Trypsin-EDTA, DMEM, fetal bovine serum (FBS), and penicillin-streptomycin were purchased from Gibco Co (Invitrogen, Carlsbad, CA, USA). DMSO, CAPE and chrysin were purchased from Sigma Chemical Co. (St. Louis, MO, USA). Ethanolic extract of propolis (EEP) obtained from fresh propolis samples collected from Dinaran area (Iran) (13). Other materials and chemical reagents used to conduct this study were purchased from laboratory reagents providers in Iran. MTT test was previously carried out to determine the concentration of the compounds in which the cells viability was normal and had no effect on the cytotoxicity assays $(13,14)$. The test reagents were dissolved to prepare three stock solutions in DMSO for each compound (CAPE $100 \mu \mathrm{M}$, chrysin 100 $\mu \mathrm{M}$, and EEP $100 \mu \mathrm{g} / \mathrm{mL}$ ), and stored in aliquots at $-20^{\circ} \mathrm{C}$. They were diluted with fresh culture medium before use and added to the micro-plates at specific concentrations.

Cell line and cell culture conditions

AGS cell line was purchased from Royan Institute, Tehran, Iran. The cells were maintained at exponential growth at $37^{\circ} \mathrm{C}$, in DMEM, supplemented with heat inactivated $10 \%$ FBS and exposure to 5\% CO2. Moreover, penicillin and streptomycin $1 \%$ were added to the culture medium. The culture medium of the cells renewed every second day.

Cell growth assay

The growth characteristics of the AGS cell lines were previously described by Amini-Sarteshnizi et al. $(13,14)$.

RNA extraction and qRT-PCR

Total cellular RNA was extracted from AGS cells treated with increasing doses of EEP, CAPE, and chrysin $(10,15,30$ $\mu \mathrm{M}$ for CAPE, 20, 30, and $40 \mu \mathrm{g} / \mathrm{mL}$ for EEP, and 15, 20, and $30 \mu \mathrm{M}$ for chrysin) after 72 hours, using Biozol Total RNA Extraction Reagent kit (Qiagen, Germany). RNA was quantified with a nanodrop 1000 spectrophotometer. The purity of the extracted RNA was demonstrated using 260/280 and 260/230 wavelength ratios, which are commonly in the range of 1.8-2.2. cDNA synthesis was conducted by using moloney murine leukemia virus (MMLV) reverse transcriptase (Fermentas, Vilnius, Lithuania) with oligo-dT primers. qRT-PCR for PLD1 and glyceraldehyde 3-phosphate dehydrogenase (GAPDH) transcripts were performed using specific primers. The thermal cycle consisted of an initial denaturation step at $95^{\circ} \mathrm{C}$ for 10 minutes, followed by 45 amplification cycles consisting of denaturation at $95^{\circ} \mathrm{C}$ for 15 seconds, annealing at $60^{\circ} \mathrm{C}$ for 20 seconds, and an extension at $72^{\circ} \mathrm{C}$ for 25 seconds. The PCR products were isolated by agarose gel electrophoresis, colored with ethidium bromide, and became visible under the ultraviolet light. To evaluate the effects of CAPE, chrysin, and EEP on PLD1 expression in AGS cells, relative quantitative PCR and comparative Ct methods, using Maxima SYBR Green/Rox QPCR Master Mix (2X) kit (Fermentase), were performed and analyzed on Rotor-Gene 3000 (Corbett Robotics, Australia). All tests were carried out at least in triplicate ( $100 \mathrm{ng}$ total RNA per well). Template control was run in each experiment. The primer sequence of PLD1 and GAPDH are listed in Table 1. Relative mRNA levels of the target gene in each sample were normalized to its GAPDH content: Ratio= (Etarget) $\Delta \mathrm{Ct}$ target (control-treatment)/ (Ereference) $\Delta \mathrm{Ct}$ reference (control-treatment) $(15,16)$.

Statistical analysis

Data on the cell populations with different treatments and conditions were analyzed using GraphPad Prism software (v5.01, USA) and Kruskal-Wallis test followed by posthoc comparisons and Dunn's multiple comparison.

\section{Results}

Growth characteristics of AGS cell line and optimization of qRT-PCR

The growth characteristics of the AGS cell line were previously described $(13,14)$. Prior to the quantitative analysis, optimization procedures were carried out for qRT-PCR on the EEP, chrysin, and CAPE treated AGS cell lines. Using specific primers for human PLD1 and

Table 1. The sequence of the designed primers for amplification of the target genes for qRT-PCR

\begin{tabular}{lll}
\hline Target gene & Primer sequence & Size of the amplicon \\
\hline Phospholipase D1 (PLD1) & 5'-GCTGGGAAAGCGTGACAGTGA-3' & 150bp \\
& 5'-AGCCAAGGACAACCCTAAAGCAG-3' & $112 \mathrm{bp}$ \\
glyceraldehyde 3-phosphate dehydrogenase & 5'-GTGAAGGTCGGAGTCAAC-3' & \\
$($ GAPDH $)$ & 5'-GTTGAGGTCAATGAAGGG-3' & \\
\hline
\end{tabular}


GAPDH genes, electrophoresis of the PCR products was conducted on acrylamide gel which demonstrated single bands with the expected sizes for amplified PLD1 (150 $\mathrm{bp})$ and GAPDH (112 bp) segments. Expression analysis of the genes showed a unique melting curve without any primer dimer for all the inspected genes (Figure 1), which was further confirmed by acrylamide gel separation and staining. Standard curve was plotted for consistent realtime PCR results (Figure 1).

Expression of PLD1 gene in AGS cell specimens After optimization of qRT-PCR, the effects of CAPE, chrysin, and EEP on PLD1 gene expression (mRNA) were investigated. CAPE decreased the mRNA level of PLD1 gene in a dose-dependent manner, in comparison with the control in the AGS cell line $(P=0.04)$ whereas no change was observed in the presence of EEP $(P=0.3)$ and chrysin $(P=0.08)$ in this cell line (Figure 2$)$.

\section{Discussion}

The current study is the first to show the effects of CAPE, chrysin, and EEP on PLD1 gene regulation in the AGS cell line. According to our results, CAPE (with the concentrations of $30 \mu \mathrm{M}$ ) down-regulated the expression

(a)

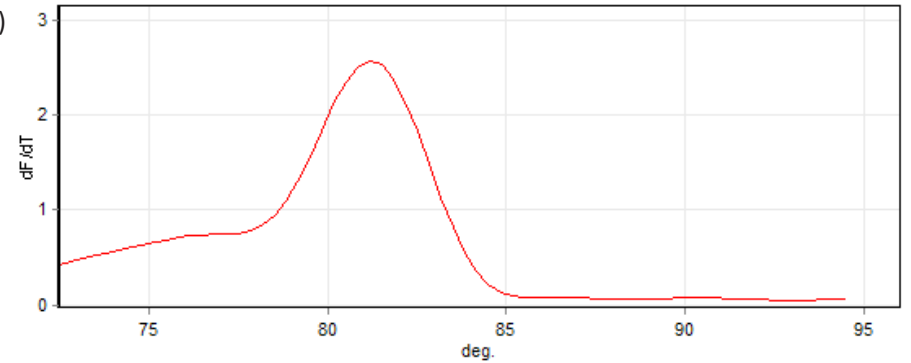

(b)

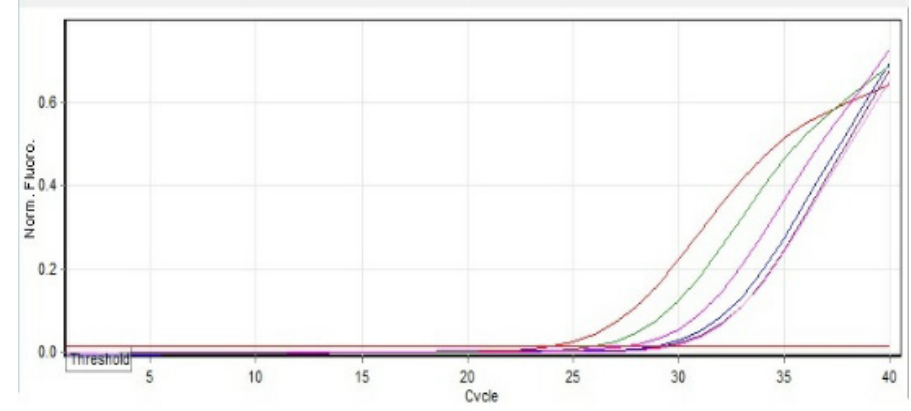

(c)

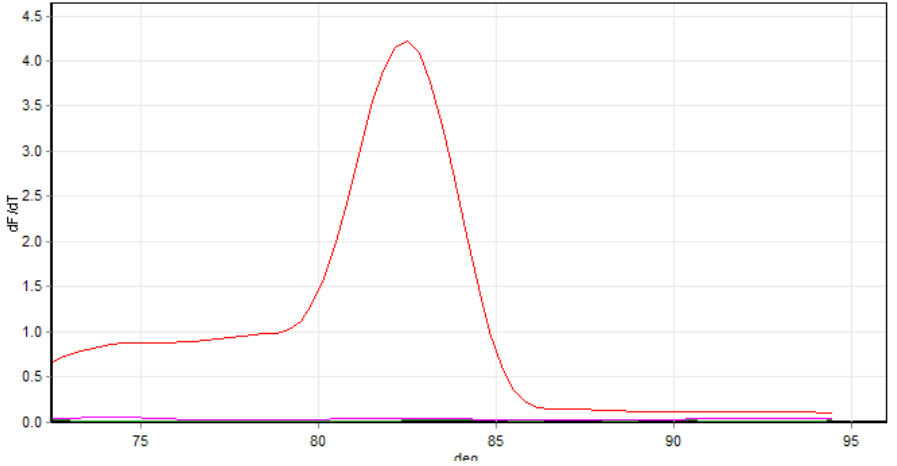

(d)

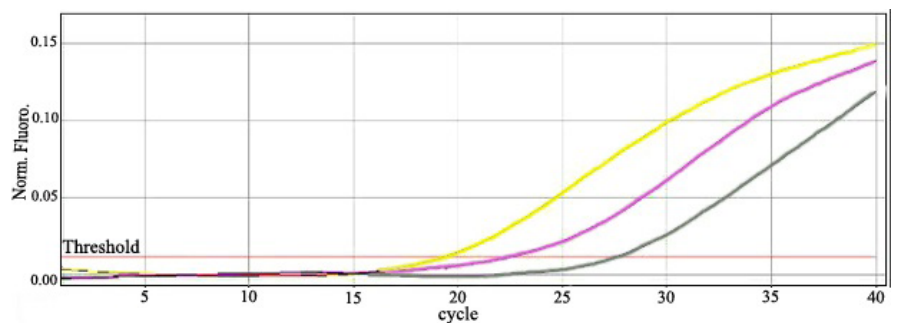

Figure 1. Optimization of quantitative RT-PCR (qRT-PCR). A unique melting curve without primer dimers showing specific amplification of glyceraldehyde 3-phosphate dehydrogenase (GAPDH) (a) and phospholipase D1 (PLD1) (c) on qRT-PCR. Standard curves of a cDNA dilution series for determination of amplification efficiencies of PLD1 (b) and GAPDH (d). 
(a)

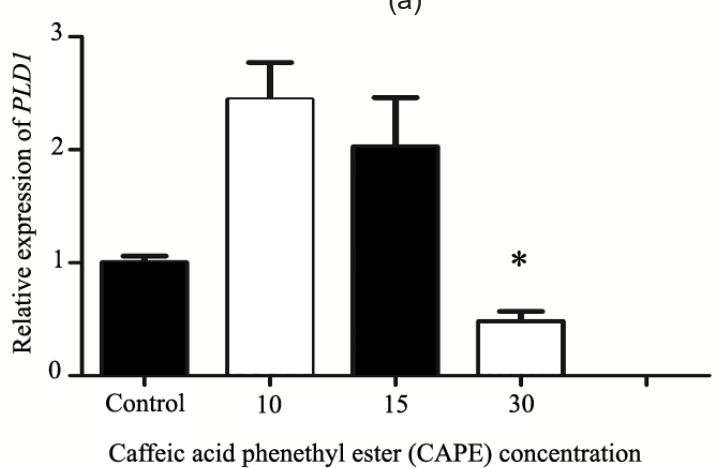

(b)

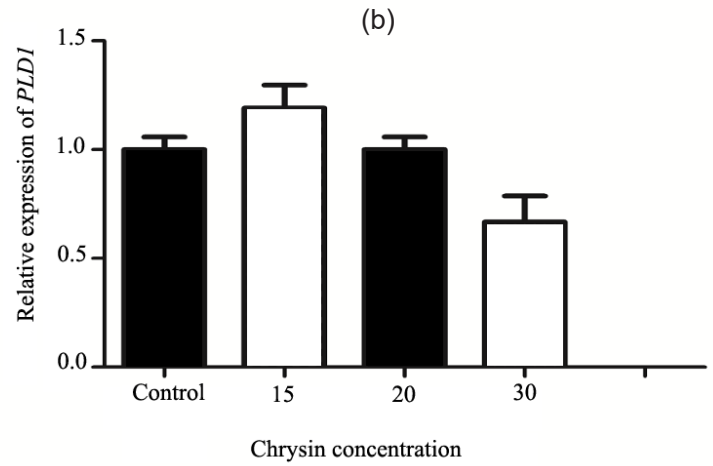

(c)

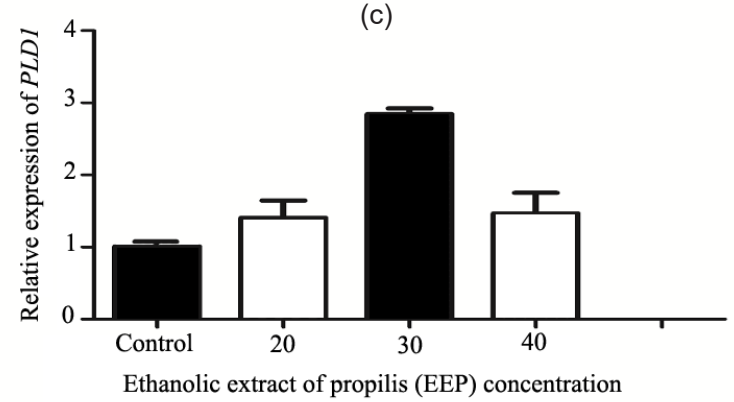

Figure 2. Effects of caffeic acid phenethyl ester (CAPE) (a), chrysin (b), and ethanolic extract of propolis (EEP) (c) on expression of PLD1 gene in AGS cell lines.

Data are expressed as mean \pm standard deviation; * $P<0.05$ compared with the corresponding value of control group.

of PLD1 gene and subsequently inhibited the proliferation of gastric cancer cell lines. CAPE is a potent antioxidant agent isolated from honeybee hive propolis. Several studies have shown that CAPE has the potential for the treatment of several cancers (17). The compound has already been reported to suppress the cell proliferation of prostate cancer cell lines (18). A study showed that CAPE down-regulated PLD1 expression at the transcriptional level and suppressed the proliferation of glioma cells (19). Accordingly, the inhibition of PLD1 activity may occur via direct binding of the catechol moiety in CAPE to cysteine 837 in the PLD1 $(19,20)$. Therefore, this study confirmed the evidence on the down-regulation of PLD1 gene by CAPE. The phospholipase superfamily is defined by a conserved catalytic site and a common transphosphatidylation activity at phosphodiester bonds. Studies have reported that PLD1 promoted RAS and ERK activation and transformation in epithelial cells via interaction with PEA-1S (20). Another study demonstrated that PLD1 was required for NF-kB activation, due to inducing the activation and expression of $M M P 2$, and promoted the invasion of the glioma cells (21). Rebamipide down-regulates the expression and enzymatic activity of PLD1 and inhibits the proliferation of gastric cancer cells. A study reported that rebamipide inhibited the transactivation of NF-kB in the AGS and MKN-1 gastric cancer cells. Such PLD1 suppression may be due to the inhibition of NF-kB activity by rebamipide (22).

Chrysin, a naturally occurring flavone, which is found in honey and plant extracts, has been shown to possess anticancer properties (23). Chrysin exerts its effects through the selective modulation of multiple cell signaling pathways which are related to the survival, inflammation and metastasis of cancer cells. Chrysin is able to kill cancer cells of several histotypes including hematologic, lung, colon, liver, and breast cancers as well as glioblastoma. Chrysin was found to significantly sensitize the TNFalpha-induced apoptosis in human colorectal cancer cell line HCT-116, human nasopharyngeal carcinoma cell line CNE-1, and human liver cancer cell line HEPG2; in which such sensitization is closely related to inhibitory effect on NF-kB activation (24). On the other hand, NF-kB binds to and activates the PLD1 promoter; therefore, chrysin is likely to exert its anticancer activity through PLD1 downregulation (19). EEP is one of the sources of phenolic acids and flavonoids. Several mechanisms were offered to explain the overall cancer-preventive and antitumor effects of propolis and its phenolic components (25). A study reported that EEP inhibited the growth and induced apoptosis in HeLa cancer cell line in a dose-dependent manner (25). In the present study, however, no correlation between EEP or chrysin and PLD1 gene expression was observed. It can be hypothesized that EEP and chrysin may exert their effects on the protein activity of PLD1. PEA-1S, a binding partner of PLD1, promotes H-RASmediated cell transformation via the enhanced expression and activation of PLD1 (20). It is likely that PEA-1S inhibits the effects of EEP and chrysin.

\section{Conclusion}

The results of this study indicated that CAPE might be associated with anti-cancer outcome by targeting PLD1 in the AGS cell line. This study showed that CAPE influenced on PLD1 gene expression and down-regulated its expression in a dose-dependent manner. Therefore, it can be proposed that we may be able to use CAPE as an adjuvant therapy for gastric cancer. However, we 
recommend further research to evaluate PLD1 protein activity, so that more definite arguments can be made on the effects of the CAPE on PLD1 expression. Regarding chrysin and EEP, although no association between them and PLD1 expression was observed, research on the effect of these two compounds on the translation and activity of the PLD1 protein may show promising results and enable us to introduce more effective therapies for different cancers.

\section{Acknowledgments}

Authors would like to thank the Vice-chancellor for the Research and Technology Deputy of the Shahrekord University of Medical Sciences for funding this study.

\section{Authors' contributions}

HJG: Experimental design, collection and/or assembly of data, data analysis, interpretation, and manuscript writing. AJ: Data analysis, interpretation, and manuscript writing. NAS: Data analysis and interpretation. HT: Conception and design, financial support, data analysis, interpretation, manuscript writing, and final approval of the manuscript.

\section{Conflict of interests}

Authors declare no conflict of interests.

\section{Ethical considerations}

This study was only performed on commercially available cell lines and no human specimens or animal models were examined. The study was approved by the Research Ethics Committee of the Shahrekord University of Medical Sciences (Approval code: 94-1-6)

\section{Funding/Support}

This work was supported by a grant from the Shahrekord University of Medical Sciences (grant number: 2264).

\section{References}

1. Sajadpoor Z, Amini-Farsani Z, Teimori H, Shamsara M, Sangtarash MH, Ghasemi-Dehkordi P, et al. Valproic acid promotes apoptosis and cisplatin sensitivity through downregulation of H19 noncoding RNA in ovarian A2780 cells. Appl Biochem Biotechnol. 2018;185(4):1132-44. doi: 10.1007/s12010-017-2684-0.

2. Viotti M, Wilson C, McCleland M, Koeppen H, Haley B, Jhunjhunwala S, et al. SUV420H2 is an epigenetic regulator of epithelial/mesenchymal states in pancreatic cancer. J Cell Biol. 2018;217(2):763-77. doi: 10.1083/jcb.201705031.

3. Marchese S, Polo A, Ariano A, Velotto S, Costantini S, Severino L. Aflatoxin B1 and M1: Biological properties and their involvement in cancer development. Toxins (Basel). 2018;10(6). doi: 10.3390/toxins 10060214.

4. Amini-Farsani Z, Sangtarash MH, Shamsara M, Teimori H. MiR-221/222 promote chemoresistance to cisplatin in ovarian cancer cells by targeting PTEN/PI3K/AKT signaling pathway. Cytotechnology. 2018;70(1):203-13. doi: 10.1007/s10616-017-0134-z.

5. Khan N, Afaq F, Mukhtar H. Cancer chemoprevention through dietary antioxidants: progress and promise. Antioxid Redox Signal. 2008;10(3):475-510. doi: 10.1089/ ars.2007.1740.

6. Huang WY, Cai YZ, Zhang Y. Natural phenolic compounds from medicinal herbs and dietary plants: potential use for cancer prevention. Nutr Cancer. 2010;62(1):1-20. doi: 10.1080/01635580903191585.

7. Markiewicz-Zukowska R, Car H, Naliwajko SK, Sawicka D, Szynaka B, Chyczewski L, et al. Ethanolic extract of propolis, chrysin, CAPE inhibit human astroglia cells. Adv Med Sci. 2012;57(2):208-16. doi: 10.2478/v10039-012-0042-6.

8. Sanderson JT, Clabault H, Patton C, Lassalle-Claux G, JeanFrancois J, Pare AF, et al. Antiproliferative, antiandrogenic and cytotoxic effects of novel caffeic acid derivatives in LNCaP human androgen-dependent prostate cancer cells. Bioorg Med Chem. 2013;21(22):7182-93. doi: 10.1016/j. bmc.2013.08.057.

9. Rzepecka-Stojko A, Kabala-Dzik A, Mozdzierz A, Kubina R, Wojtyczka RD, Stojko R, et al. Caffeic Acid phenethyl ester and ethanol extract of propolis induce the complementary cytotoxic effect on triple-negative breast cancer cell lines. Molecules. 2015;20(5):9242-62. doi: 10.3390/molecules20059242.

10. Khoo BY, Chua SL, Balaram P. Apoptotic effects of chrysin in human cancer cell lines. Int J Mol Sci. 2010;11(5):218899. doi: 10.3390/ijms11052188.

11. Cockcroft S. Signalling roles of mammalian phospholipase D1 and D2. Cell Mol Life Sci. 2001;58(11):1674-87. doi: 10.1007/pl00000805.

12. Park MH, Ahn BH, Hong YK, Min do S. Overexpression of phospholipase D enhances matrix metalloproteinase-2 expression and glioma cell invasion via protein kinase $\mathrm{C}$ and protein kinase A/NF-kappaB/Sp1-mediated signaling pathways. Carcinogenesis. 2009;30(2):356-65. doi: 10.1093/ carcin/bgn287.

13. Amini-Sarteshnizi N, Mobini-Dehkordi M, KhosraviFarsani S, Teimori H. Anticancer activity of ethanolic extract of propolis on AGS cell line. J Herbmed Pharmacol. 2015;4(1):29-34.

14. Amini-Sarteshnizi N, Zahri S, Jafari-Ghahfarokhi H, Keivani Hafshejani F, Teimori H. Morphological changes of apoptosis and cytotoxic effects induced by Caffeic acid phenethyl ester in AGS human gastric cancer cell line. J Herbmed Pharmacol. 2014;3(2):77-82.

15. Vandesompele J, De Preter K, Pattyn F, Poppe B, Van Roy N, De Paepe A, et al. Accurate normalization of real-time quantitative RT-PCR data by geometric averaging of multiple internal control genes. Genome Biol. 2002;3(7):Research0034. doi: 10.1186/gb-2002-3-7research0034.

16. Yuan JS, Reed A, Chen F, Stewart CN Jr. Statistical analysis of real-time PCR data. BMC Bioinformatics. 2006;7:85. doi: 10.1186/1471-2105-7-85.

17. Ozturk G, Ginis Z, Akyol S, Erden G, Gurel A, Akyol O. The anticancer mechanism of caffeic acid phenethyl ester (CAPE): review of melanomas, lung and prostate cancers. Eur Rev Med Pharmacol Sci. 2012;16(15):2064-8.

18. Liu CC, Hsu JM, Kuo LK, Chuu CP. Caffeic acid phenethyl 
ester as an adjuvant therapy for advanced prostate cancer. Med Hypotheses. 2013;80(5):617-9. doi: 10.1016/j. mehy.2013.02.003

19. Park MH, Kang DW, Jung Y, Choi KY, Min do S. Caffeic acid phenethyl ester downregulates phospholipase D1 via direct binding and inhibition of NFkappaB transactivation. Biochem Biophys Res Commun. 2013;442(1-2):1-7. doi: 10.1016/j.bbrc.2013.09.105.

20. Kang DW, Choi KY, Min do S. Functional regulation of phospholipase D expression in cancer and inflammation. J Biol Chem. 2014;289(33):22575-82. doi: 10.1074/jbc. R114.569822.

21. Armutcu F, Akyol S, Ustunsoy S, Turan FF. Therapeutic potential of caffeic acid phenethyl ester and its antiinflammatory and immunomodulatory effects (Review). Exp Ther Med. 2015;9(5):1582-8. doi: 10.3892/ etm.2015.2346.
22. Kang DW, Min G, Park DY, Hong KW, Min do S. Rebamipide-induced downregulation of phospholipase D inhibits inflammation and proliferation in gastric cancer cells. Exp Mol Med. 2010;42(8):555-64. doi: 10.3858/ emm.2010.42.8.056.

23. Sawicka D, Car H, Borawska MH, Niklinski J. The anticancer activity of propolis. Folia Histochem Cytobiol. 2012;50(1):25-37. doi: 10.2478/18693.

24. Kasala ER, Bodduluru LN, Madana RM, V AK, Gogoi R, Barua CC. Chemopreventive and therapeutic potential of chrysin in cancer: mechanistic perspectives. Toxicol Lett. 2015;233(2):214-25. doi: 10.1016/j.toxlet.2015.01.008.

25. Szliszka E, Czuba ZP, Domino M, Mazur B, Zydowicz G, Krol W. Ethanolic extract of propolis (EEP) enhances the apoptosis- inducing potential of TRAIL in cancer cells. Molecules. 2009;14(2):738-54. doi: 10.3390/molecules. 